\title{
DETERMINATION OF THE CHARACTERISTIC TRANSFORMATION TEMPERATURES OF THE BIOCOMPATIBLE SHAPE MEMORY
}

\author{
ALLOYS \\ Dejan Tanikić ${ }^{1}$, Miodrag Manić ${ }^{2}$, Saša Ranđelović ${ }^{3}$, Dalibor Đenadić ${ }^{4}$, Darko Brodić ${ }^{5}$ \\ ${ }^{1}$ University of Belgrade, Technical Faculty in Bor, V.J. 12, 19210 Bor, Serbia \\ ${ }^{2}$ University of Niš, Faculty of Mechanical Engineering, A. Medvedeva 14, 18000 Niš, Serbia \\ ${ }^{3}$ University of Niš, Faculty of Mechanical Engineering, A. Medvedeva 14, 18000 Niš, Serbia \\ ${ }^{4}$ University of Belgrade, Technical Faculty in Bor, V.J. 12, 19210 Bor, Serbia \\ ${ }^{5}$ University of Belgrade, Technical Faculty in Bor, V.J. 12, 19210 Bor, Serbia
}

\begin{abstract}
Shape memory alloys are specific materials which have the ability to change their shape and transform to some memorized state, which is caused by changing in their temperature. This materials are often biocompatible which enables their use in medicine. Martensite thermoelastic transformation from martensite to austenite, and vice versa, is a key process which enables shape changing of shape memory alloys. Starting and finishing temperatures of the martensite transformation, as well as starting and finishing temperatures of the austenite transformation depends on the physical and chemical characteristic of the alloy. This work considers the possibility of using the artificial intelligence based system for predicting the characteristic transformation temperatures of the shape memory alloys.
\end{abstract}

Keywords: shape memory alloys, temperature, martensite thermoelastic transformation

\section{INTRODUCTION}

The main characteristic of the Shape Memory Alloys (SMA) is their shape transformation, caused by changes in the environment temperature, i.e. their returning in some memorized shape. Depending on the environment temperature and amount of the applied load, shape memory alloys can be present in two different crystal structures, i.e. phases [1]. Martensite is the phase which is present on the low temperatures, while the high temperature phase is austenite. The shape memory effect is noticed in the thirties years of the past century on the copper based alloys $(\mathrm{Cu}-\mathrm{Zn}$ and $\mathrm{Cu}-\mathrm{Sn}$ ) [2]. But one of the most frequently used shape memory alloy, well known as Nitinol (alloy on the basis of nickel and titanium) was revealed in the sixties years of the past century in the Naval Ordnance Laboratory in USA, which is commonly assigned as the origin of the investigation in the shape memory alloys field.

The first document of the large shape memory alloys usage was reported in 1971. for manufacturing of the couplings which connects titanium tube installations in the Grumman F-14 airplane [3]. The main problem which was overcome in this way is joining of the titanium tubes, which are used due to a recommendation for the lightening of the whole construction. That was a typical example of the usage of scientific knowledge for concrete industrial problems solving. In the early eighties of the past century, the significant usage of the shape memory alloys for manufacturing the valves for air-condition devices was noticed in Japan. At the same time starts the large usage of SMAs primarily in dental, and after that for all other medical applications. There is always an aspiration for the usage of new materials, which was primarily developed for the military and aircraft industry, in medicine, for manufacturing of the compatible and functional implants, with a goal to enhance the quality of the patient's life. Fig. 1 shows SMA stent and its shape before and after appliance. The stent is on the low temperature in the deformed shape beforehand. After appliance, on the body temperature, it takes the final form, enabling smooth blood flow. 


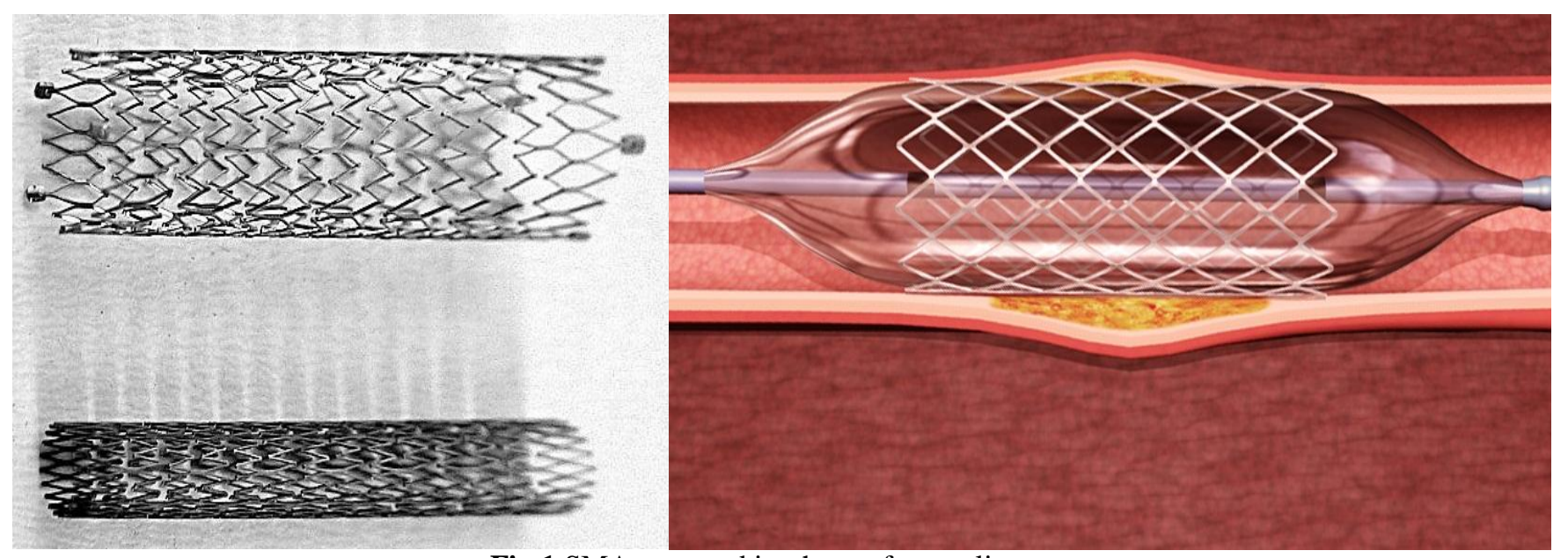

Fig 1 SMA stent and its shape after appliance

\section{SHAPE}

\section{FUNDAMENTALS}

The basic principle of the SMA functionality is the phase transformation in the solid state, which is known as the martensite thermoelastic transformation from martensite to austenite and vice versa [4]. As mentioned earlier, the low temperature phase is martensite, while the high temperature phase is austenite, while phase transformations from martensite to austenite and vice versa occurs on the exactly defined temperatures, which depends on the physical and chemical characteristics of the alloy. Different alloys have different characteristic temperatures. There are four characteristic temperatures needed for understanding the principle of the SMA functionality: $M_{s}$ - start point of the martensite phase forming, $M_{f}$ - finish point of the martensite phase forming, $A_{s}$ - start point of the austenite phase forming and $A_{f}$ - finish point of the austenite phase forming. It is almost impossible to predict forward the characteristic temperatures of the transformation. For this purpose it is primarily necessary to produce wanted alloy, and determine characteristic temperatures after that, using some of the well known methods, such as: differential thermal analysis -
DTA, differential scanning calorimetry - DSC, thermodilatometry - TD... [5].

Shape memory effect in materials can be realized as:

- One-way shape memory effect

- Two-way shape memory effect

- Superthermoelastic effect

One-way shape memory effect implies the materials ability to memorize high temperature shape.

Two-way shape memory effect implies the ability of the material to memorize two different shapes - low temperature shape and high temperature shape.

Superthermoelastic effect comprehends superelastic and superthermic effects. Some materials have the ability to accept very large amount of load and, after unloading, they returns to the primarily shape, which is denoted as superelasticity or pseudoelasticity.

One-way shape memory effect is based on the recovering of the primarily state by simply heating of the material, which is shown in Fig. 2.

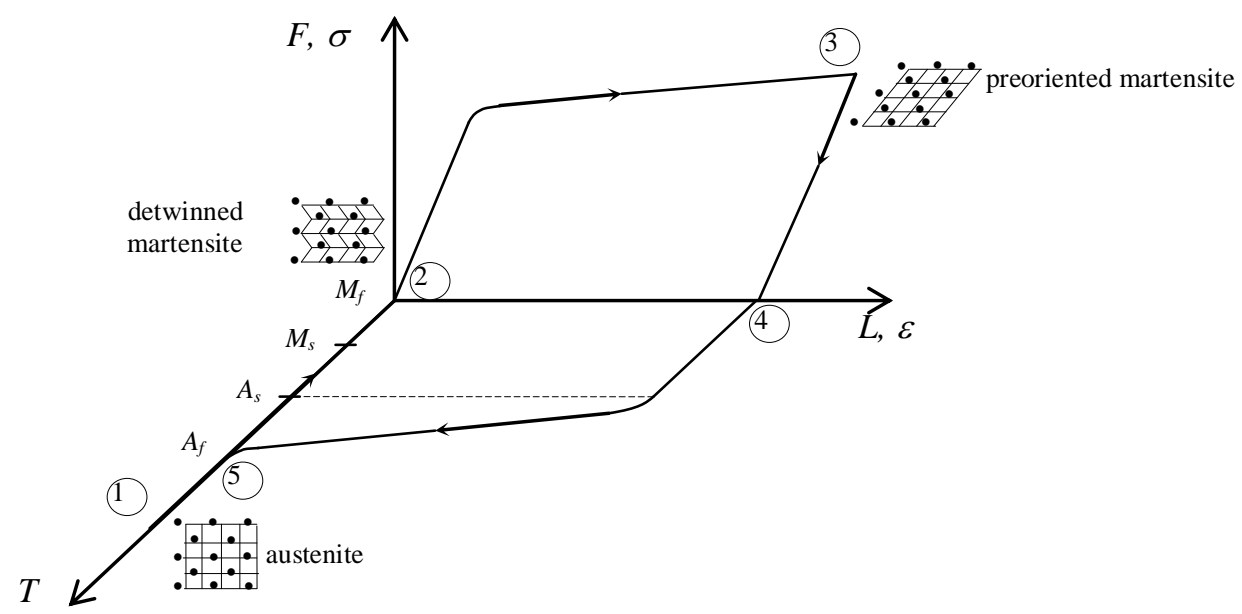

Fig. 2. One-way shape memory effect 
At the beginning, the material is in the austenite state on the room temperature (point 1). Firstly, the specimen is cooling and austenite to martensite transformation begins at temperature $-M_{s}$. With further cooling, without any loading, the specimen reaches its finish point of the martensite phase formation $-M_{f}$. At the end of this process, the specimen is in the detwinned martensite phase (point 2). On that, low temperature, the specimen is deformed using the external forces $-F$, which leads to the changes in the specimen dimensions $-L$ (point 3 ). At this point, the material is in the martensite phase, and it is so called preoriented martensite. The specimen retains deformed shape even after unloading (point 4). Heating of the specimen leads to the start point of the austenite phase formation $-A_{s}$, when martensite to austenite phase transformation begins. This process is completely finished at the finish point of the austenite phase forming $-A_{f}$. Finally, the specimen is returned to its primarily, undeformed shape (point 5).

\subsection{Characteristic Austenite-Martensite}

\section{Transformation Temperatures}

There is a wide range of known shape memory alloys which express less or more shape memory effect. However, only those materials which can endure a significant deformation, and those which can generate a significant amount of force are commercially concerned. The most popular among them are nickel-titanium alloys (Ni-Ti), called nitinol, as well as alloys on the copper base, such as copper-zinc-aluminium $(\mathrm{Cu}-\mathrm{Zn}-\mathrm{Al})$ and copper-aluminium-nickel (Cu-Al-Ni). Alloys on the Ni-Ti base have significant ability of shape memory, but due to a high production cost its usage is limited.
The area of SMAs usage is depending on the characteristic temperatures of the austenite-martensite transformation. Starting and finishing temperatures of the austenitemartensite transformation depends on the physical and chemical characteristics of the alloy, and it is very hard to predict them beforehand. For example, increasing the share of $\mathrm{Ni}$ from $50 \%$ to only $50,5 \%$, in the alloy which consist only $\mathrm{Ni}$ and $\mathrm{Ti}$, the starting temperature of the martensite transformation is decreased for about $93^{\circ} \mathrm{C}$, while further increasing of the $\mathrm{Ni}$ share on $51 \%$ causes decreasing the starting point of the martensite transformation for an extra $75^{\circ} \mathrm{C}$. So, characteristic temperatures changes are not linear, and it is very hard to model them. The modelling process is additionally complicating when alloy considers more than two elements. Taking in consideration the fact that determining the characteristic temperatures of the austenitemartensite transformation needs large examinations and a lot of time, it is possible to establish mathematical model which can, depending on the alloy chemical composition, predict starting and finishing temperatures of the austenitemartensite transformation.

This paper presents the possibility of using the artificial intelligence based system for predicting the characteristic transformation temperatures of the shape memory alloys. Specifically artificial neural network was used. For this purpose, the data about certain alloys and their characteristic temperatures, obtained from the appropriate literature, shown in Table 1, was used [6].

Table 1 Characteristic temperatures of the austenite-martensite transformation of different SMA

\begin{tabular}{|l|l|l|l|l|l|l|l|l|l|l|l|}
\hline $\begin{array}{l}\mathbf{T i} \\
(\boldsymbol{\%})\end{array}$ & $\begin{array}{l}\mathbf{N i} \\
(\boldsymbol{\%})\end{array}$ & $\begin{array}{l}\mathbf{C u} \\
(\boldsymbol{\%})\end{array}$ & $\begin{array}{l}\mathbf{N b} \\
(\boldsymbol{\%})\end{array}$ & $\begin{array}{l}\mathbf{H f} \\
(\boldsymbol{\%})\end{array}$ & $\begin{array}{l}\mathbf{Z r} \\
(\boldsymbol{\%})\end{array}$ & $\begin{array}{l}\mathbf{P d} \\
(\boldsymbol{\%})\end{array}$ & $\begin{array}{l}\mathbf{P t} \\
(\boldsymbol{\%})\end{array}$ & $\begin{array}{l}\mathbf{M}_{\mathbf{f}} \\
\left({ }^{\circ} \mathbf{C}\right)\end{array}$ & $\begin{array}{l}\mathbf{M}_{\mathbf{s}} \\
\left({ }^{\circ} \mathbf{C}\right)\end{array}$ & $\begin{array}{l}\mathbf{A}_{\mathbf{s}} \\
\left({ }^{\circ} \mathbf{C}\right)\end{array}$ & $\begin{array}{l}\mathbf{A}_{\mathbf{f}} \\
\left({ }^{\circ} \mathbf{C}\right)\end{array}$ \\
\hline 50 & 50 & 0 & 0 & 0 & 0 & 0 & 0 & 15 & 55 & 80 & 89 \\
\hline 49,5 & 50,5 & 0 & 0 & 0 & 0 & 0 & 0 & -78 & -19 & 9 & 53 \\
\hline 49 & 51 & 0 & 0 & 0 & 0 & 0 & 0 & -153 & -114 & -89 & -40 \\
\hline 49 & 41 & 10 & 0 & 0 & 0 & 0 & 0 & 8 & 30 & 35 & 50 \\
\hline 50 & 40 & 10 & 0 & 0 & 0 & 0 & 0 & 21 & 41 & 53 & 67 \\
\hline 44 & 47 & 0 & 9 & 0 & 0 & 0 & 0 & -175 & -90 & -85 & -35 \\
\hline 42,2 & 49,8 & 0 & 0 & 8 & 0 & 0 & 0 & 50 & 69 & 111 & 142 \\
\hline 40,7 & 49,8 & 0 & 0 & 9,5 & 0 & 0 & 0 & 61 & 90 & 118 & 159 \\
\hline 40,2 & 49,8 & 0 & 0 & 10 & 0 & 0 & 0 & 103 & 128 & 182 & 198 \\
\hline 35,2 & 49,8 & 0 & 0 & 15 & 0 & 0 & 0 & 95 & 136 & 140 & 210 \\
\hline 30,2 & 49,8 & 0 & 0 & 20 & 0 & 0 & 0 & 127 & 174 & 200 & 276 \\
\hline 48 & 47 & 0 & 0 & 0 & 5 & 0 & 0 & 20 & 65 & 75 & 138 \\
\hline 43 & 47 & 0 & 0 & 0 & 10 & 0 & 0 & 45 & 100 & 113 & 165 \\
\hline 38 & 47 & 0 & 0 & 0 & 15 & 0 & 0 & 100 & 175 & 175 & 230 \\
\hline 33 & 47 & 0 & 0 & 0 & 20 & 0 & 0 & 205 & 275 & 265 & 330 \\
\hline 50 & 0 & 0 & 0 & 0 & 0 & 50 & 0 & 550 & 563 & 580 & 591 \\
\hline 50 & 20 & 0 & 0 & 0 & 0 & 30 & 0 & 208 & 241 & 230 & 241 \\
\hline 50 & 10 & 0 & 0 & 0 & 0 & 40 & 0 & 387 & 403 & 419 & 427 \\
\hline 50 & 5 & 0 & 0 & 0 & 0 & 45 & 0 & 467 & 486 & 503 & 509 \\
\hline 50 & 45 & 0 & 0 & 0 & 0 & 0 & 5 & 10 & 29 & 36 & 49 \\
\hline 50 & 40 & 0 & 0 & 0 & 0 & 0 & 10 & -8 & 18 & -27 & 36 \\
\hline 50 & 30 & 0 & 0 & 0 & 0 & 0 & 20 & 241 & 300 & 263 & 300 \\
\hline 50 & 20 & 0 & 0 & 0 & 0 & 0 & 30 & 537 & 619 & 626 & 702 \\
\hline
\end{tabular}


3. CHARACTERISTIC

TEMPERATURES

\section{MODELLING USING THE ARTIFICIAL}

\section{NEURAL NETWORKS}

Artificial neural network (ANN) is a structure which is capable to generate appropriate output vector $O=\left[o_{1}, o_{2}, \ldots\right.$, $\left.o_{m}\right]$, depending on the input vector $I=\left[i_{1}, i_{2}, \ldots, i_{n}\right]$. It is consisted from the large or less number of processing units, called neurons. Each of the input values $x_{1}, x_{2}, \ldots, x_{r}$ are multiplied with the appropriate weight coefficients $w_{l, 1}$, $w_{l, 2}, \ldots, w_{l, r}$. The processing unit summarises this values and adds an additional value, called bias, which can be, but not obligatorily, present in the neural network. In this way, argument of the activation function can be calculated:
The output value from the neuron is calculated in the following way:

$$
y_{i}=f\left(a_{i}\right)=f\left(\sum_{j=1}^{r} x_{j} w_{i, j}+b_{i}\right)
$$

This value is an input value for the neurons of the next level, or an element of the output vector, if this processing unit is in the output level of neurons [7]. Fig. 3 shows the characteristic structure of the artificial neural network which is used for determining of the characteristic temperatures of the austenite-martensite transformations of the biocompatible alloys with different chemical composition.

$$
a_{i}=x_{1} w_{i, 1}+x_{2} w_{i, 2}+\ldots+x_{r} w_{i, r}+b_{i}
$$

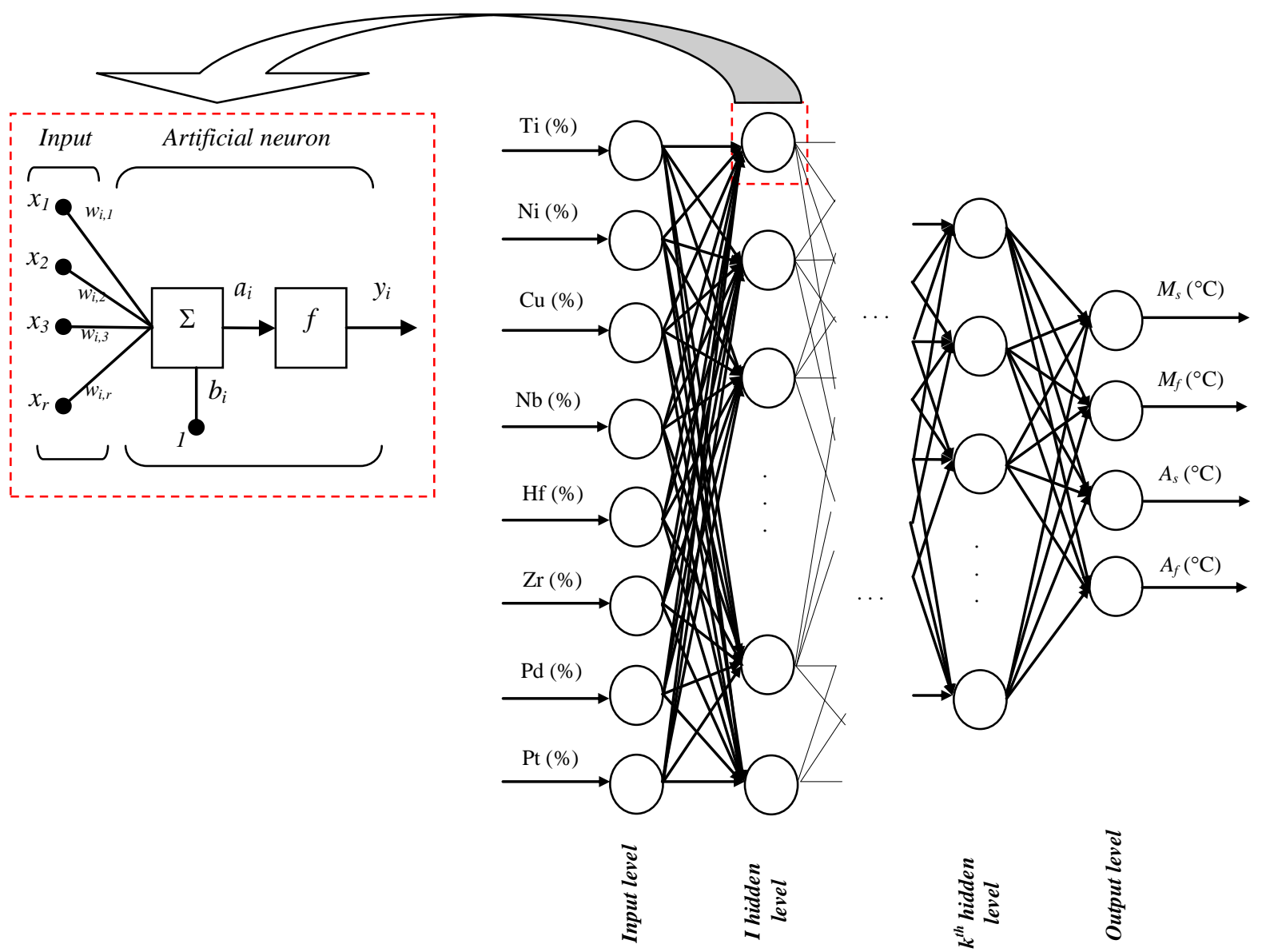

Fig. 3. ANN for determining of the characteristic temperatures of the different SMAs

The characteristic temperatures of the shape memory alloys can be determined using the model with ANN technology [8]. The first step in the artificial neural network modelling is defining input and output values. In this case, each input value represents the percentage of the respective chemical element in the alloy. On that way, the network has eight inputs, which represents percentages of the $\mathrm{Ti}, \mathrm{Ni}, \mathrm{Cu}, \mathrm{Nb}$, $\mathrm{Hf}, \mathrm{Zr}, \mathrm{Pd}$ and $\mathrm{Pt}$ in the concrete alloy. The output values are characteristic temperatures of the austenite-martensite transformations, so the model has four output values: starting and finishing temperatures of the martensite phase forming and starting and finishing temperatures of the austenite phase forming. All input and output values are normalized in the range $0 \div 1$.

The artificial neural network has one input and one output level, the number of the processing units in the input layer is identical to the number of the input variables -8 (each input 
value is represented by a neuron), and the number of the neurons in the output level is identical to the number of the output variables -4 . The number of the hidden neurons and the number of the neurons in them are not explicitly defined, and the optimal number of levels and neurons could be reached only by experimental tests. Generally, larger number of neurons and larger number of training cycles leads to the better performances of the network. However, this fact is not always true, because there is a danger of overfitting (the situation where the network turns into a simple table). In that case, the accuracy in the points used for network training is very high, but the main purpose of the artificial neural network - data generalization, is completely lost.

In the concrete case, the number of the neurons in the hidden level is set to 5. ANN is trained with the set of data which represents 23 SMAs (training set is consist of the 23 inputoutput combinations). $15 \%$ of this set is used for validation, and the same percentage for model testing.

The accuracy of the artificial neural networks based model can be evaluated by correlation coefficient. Correlation coefficient $(R)$ represents statistical measure of correlation among modelled and measured, i.e. real values. In this case, the average value of the correlation coefficient (including training data, as well as data used for testing and verification of the model) was $R=0,99$. Performance of the proposed
ANN model for prediction of the characteristic temperatures of the martensite-austenite transformations are shown in Fig. 4.

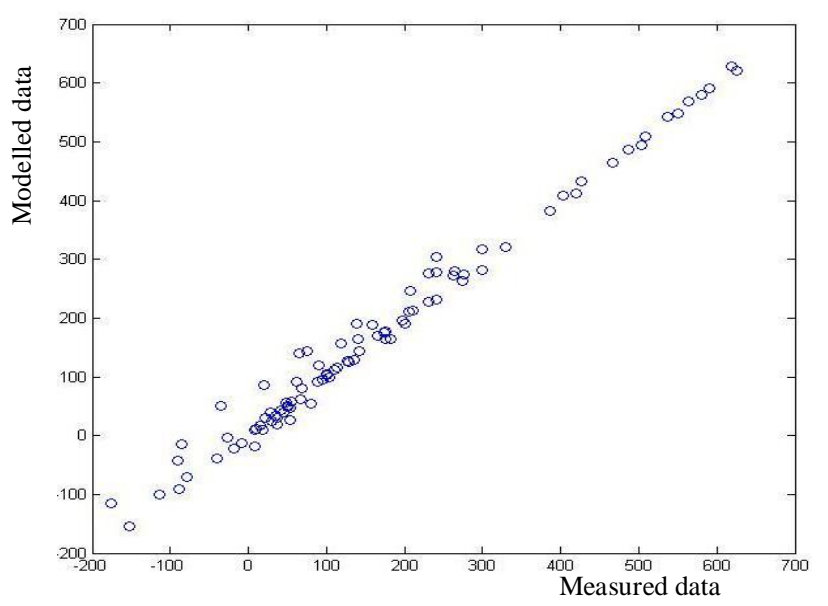

Fig. 4. Performance of the proposed ANN model for prediction of the characteristic temperatures of the martensite-austenite transformations

Measured and modelled values of the characteristic temperatures of the martensite-austenite transformations of the various SMAs are graphically represented in Fig. 5.

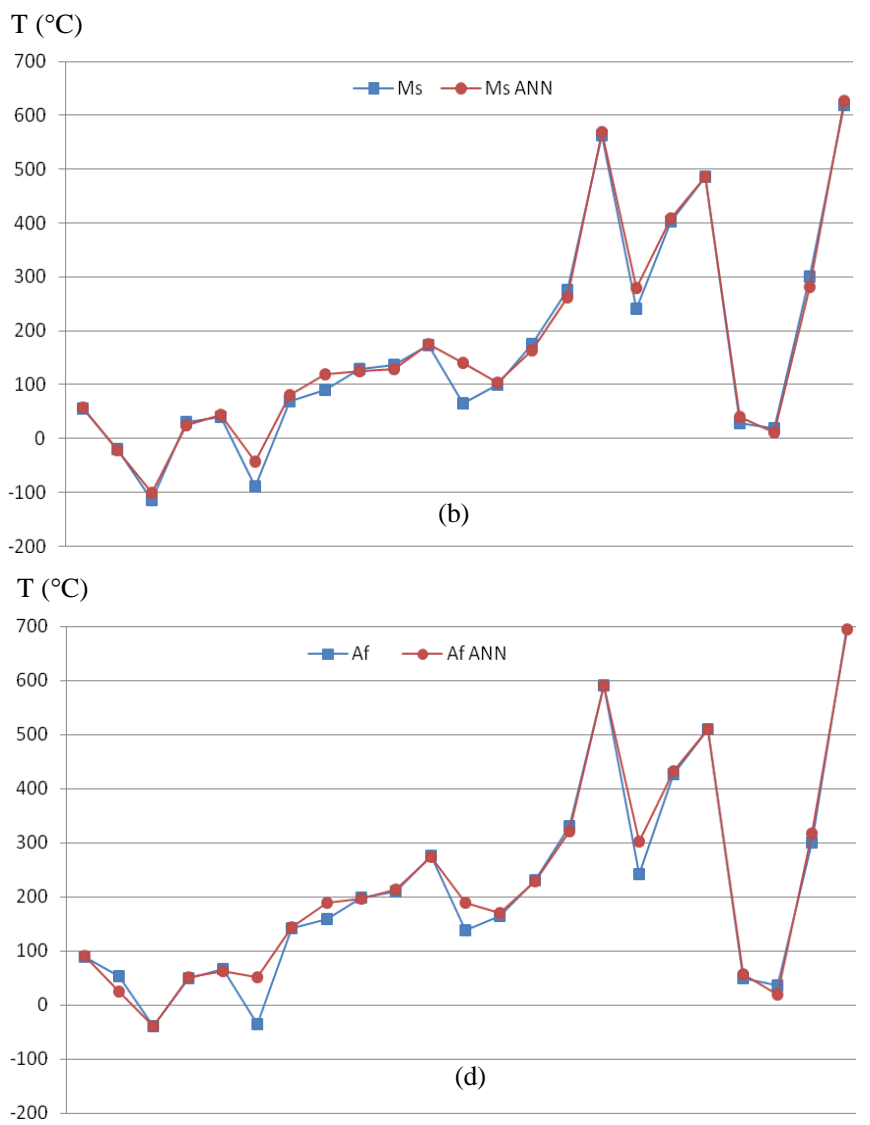

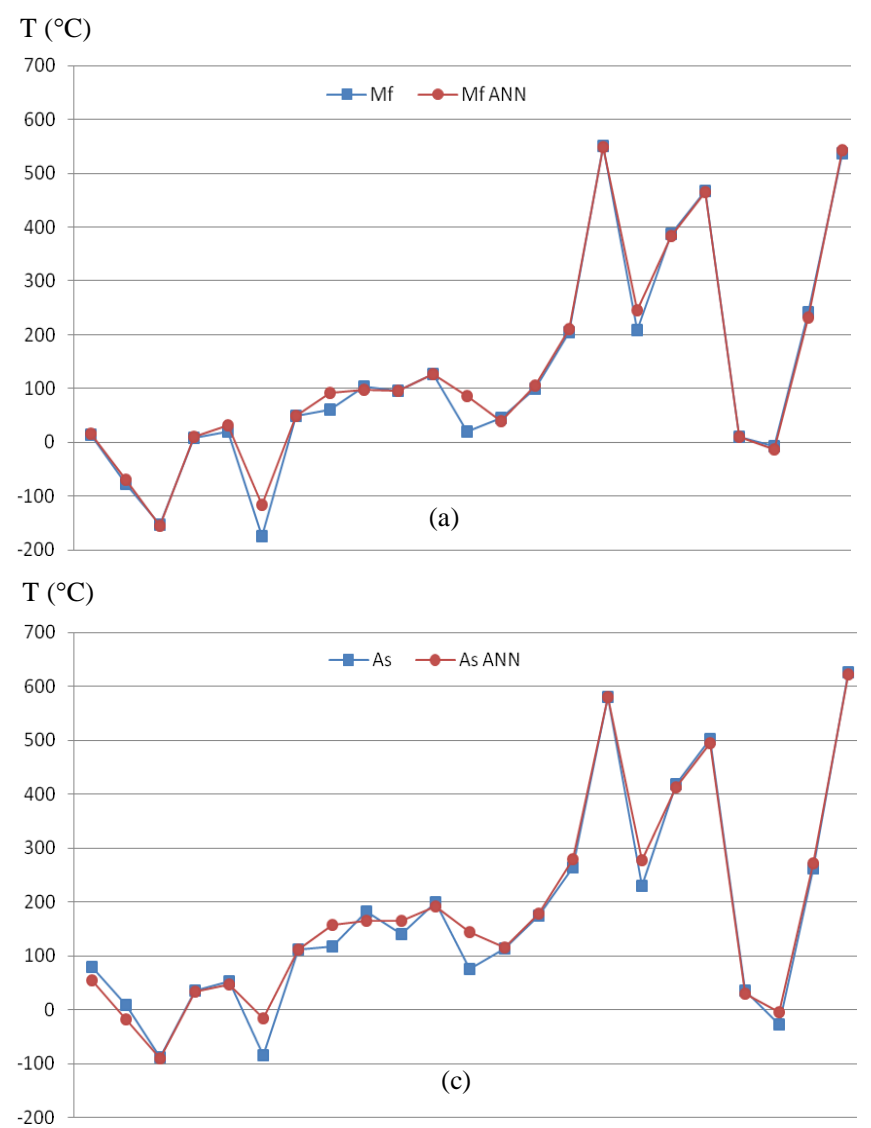

Fig. 5. Measured and modelled values of the characteristic temperatures of the various SMAs, (a) finish point of the martensite phase forming $-M_{f}$; (b) start point of the martensite phase forming $-M_{s}$; (c) start point of the austenite phase forming $-A_{s}$; (d) finish point of the austenite phase forming $-A_{f}$ 


\section{CONCLUSION}

Advantageous mechanical and physical characteristics of the shape memory alloys, as well as shape memory effect, are widely used in almost all fields of science and technique. Biocompatibility of those materials is one of the crucial characteristics which classifies them in the priority class of the materials which are used in biomedicine. Characteristic temperatures, i.e. starting and finishing temperatures of the martensite-austenite transformation of the various SMAs depend on the physical and chemical characteristics of the alloy. Those temperatures are the main factor in determining the main purpose as well as area of usage of SMA. This work shows the possibility of the usage of the artificial neural networks in order to model characteristic temperatures of the alloys which have different chemical composition. After the training phase, obtained model could be used for the prediction of the characteristic temperatures of some new alloy, without the need for producing it. This leads to the saving in the time needed for producing a new alloy, and saving in the required material.

\section{ACKNOWLEDGEMENTS}

Research work presented in the paper is funded by the Ministry of Education, Science and Technological Development of the Republic of Serbia within the projects III41017 and TR34005.

\section{REFERENCES}

[1] Kanada ,T., Enokizono, M. (1999). Fe-based magnetic shape memory alloy-sheet specimen. Journal of magnetism and magnetic materials, 196197, 349-350.

[2] Mantovani, D. (2000). Shape memory alloys: Properties and biomedical applications. JOM, 52, 3644.

[3] Melton, K. N. (1998). General applications of SMA's and smart materials in Shape memory materials. Cambridge University Press.

[4] Ochonski, W. (2010). Application of shape memory materials in fluid sealing technology. Industrial Lubrication and Tribology, 62, 99-110.

[5] Tian, Q., Wu, J. (2001). A thermal perspective of NiTi alloy under non-isothermal conditions. Materials transactions, 42, 2446-2451.

[6] Lagoudas, D. C. (2008). Shape Memory Alloys: Modeling and Engineering Applications, Springer.

[7] Tanikić, D., Manić, M., Devedžić, G., Ćojbašić, Ž. (2010). Modelling of the Temperature in the ChipForming Zone Using Artificial Intelligence Techniques. Neural Network World, 20, 171-187.

[8] Eyercioglu, O., Kanca, E., Pala, M., Ozbay, E. (2008). Prediction of martensite and austenite start temperatures of the Fe-based shape memory alloys by artificial neural networks. Journal of materials processing technology, 200, 146-152. 